\title{
STABILITY INDICATING RP-HPLC METHOD FOR \\ DETERMINATION OF PITOLISANT IN BULK AND \\ PHARMACEUTICAL DOSAGE FORM
}

\author{
P. Venkateswara Rao*, J. Leela Rani, M. Roja Kumari, \\ G. Kalyani, G. Sirisha and P. Naveen Reddy \\ Vikas College of Pharmacy, Vissannapeta, \\ Krishna District, Andhra Pradesh-521 215, India.
}

\begin{abstract}
A simple, rapid, precise, sensitive and reproducible reverse phase high performance liquid chromatography (RP-HPLC) method has been developed for the quantitative analysis of Pitolisant in pharmaceutical dosage form. Chromatographic separation of Pitolisant was achieved on Waters Alliance-e2695, by using Waters X-Bridge Phenyl, $150 \mathrm{~mm}$ x $4.6 \mathrm{~mm}, 3.5 \mu \mathrm{m}$, column and the mobile phase containing $0.1 \%$ OPA\& ACNin the ratio of $30: 70 \% \mathrm{v} / \mathrm{v}$. The flow rate was $1.0 \mathrm{ml} / \mathrm{min}$; detection was carried out by absorption at $210 \mathrm{~nm}$ using a photodiode array detector at ambient temperature. The number of theoretical plates and tailing factor for Pitolisant was NLT 2000 and should not more than 2respectively. \%Relative standard deviation of peak area of all measurements always less than 2.0. The proposed method was validated according to ICH guidelines. The method was found to be simple, economical, suitable, precise, accurate \& robust method for quantitative analysis of Pitolisant and study of its stability.
\end{abstract}

Keywords: HPLC and Pitolisant.

\section{INTRODUCTION}

Pitolisant is a selective antagonist or inverse agonist of the histamine $\mathrm{H} 3$ receptor that is used in the treatment of type 1 or 2 narcolepsy. Narcolepsy is a chronic neurological disorder that that affects 1 in 2,000 individuals and is characterized by excessive daytime sleepiness, abnormal REM sleep manifestations, sleep paralysis and hypnagogic hallucinations. ${ }^{1,2,3}$ Pitolisant chemicaly1-\{3-[3-(4-

chlorophenyl)propoxy]propyl\}piperidine show in fig: with molecular formula $\mathrm{C}_{17} \mathrm{H}_{26} \mathrm{CINO}$ and molecular weight is 295.85. Pitolisant acts as a high-affinity competitive antagonist (Ki 0.16 $\mathrm{nM})$ and as an inverse agonist (EC50 $1.5 \mathrm{nM}$ ) at the human histamine $\mathrm{H} 3$ receptor subtype. ${ }^{1}$ It is thought to bind to the antagonist binding site of $\mathrm{H} 3$ receptor, which is located within the trans-membrane core just below the extracellular loops. Piperidines forms a salt bridge with Glu206 in the membrane spanning segment and the hydroxyl of Tyr374 is $\mathrm{H}$ bonded with the central oxygen of piperidine. ${ }^{4}$ Pitolisant displays high selectivity for $\mathrm{H} 3$ receptors compared to other histamine receptor subtypes. Pitolisant also modulates acetylcholine, noradrenaline and dopamine release in the brain by increasing the levels of neurotransmitters but does not increase dopamine release in the stratal complex including nucleus accumbent. ${ }^{4,5}$

As per literature survey 2 LCMS methods are reported for the estimation of pitolisant ${ }^{8,9}$. The objective of the study is to develop accurate precise repeatable and reproducible method for simultaneous estimation of pitolisant and to validate to $\mathrm{ICH}$ guidelines and to perform the forced degradation studies ${ }^{10,11}$. 


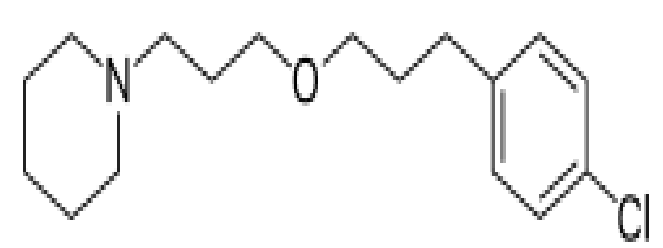

Fig. 1: Structure of pitolisant

\section{MATERIALS AND METHODS}

The reference sample of pitolisant was obtained as a gift samples and the tablet containing pitolisant $18 \mathrm{mg}$ was procured from local market. Water (HPLC grade) from Rankem and acetonitrile(HPLCgrade), orthophosphoricacid( ARgrade)methanol(Rankem), triethylamine (Rankem) from Merck Limited, $0.45 \mu \mathrm{m}$ Nylon filter was from Phenomenex 87456 were used.

\section{INSTRUMENTATION}

Waters HPLC 2695 system equipped with quaternary pumps, Photo Diode Array detector and Auto sampler integrated with Empower 2 Software. UV-VIS spectrophotometer, PG Instruments T60 with special bandwidth of 2 $\mathrm{mm}$ and $10 \mathrm{~mm}$ and matched quartz cells integrated with UV win 6 Software was used for measuring absorbanceofpitolisant solution, Electronics Balance-Denver pH meter -BVK enterprises, India Ultrasonicator-BVK enterprises

\section{CHROMATOGRAPHIC CONDITIONS}

Waters Alliance-e2695, by using Waters XBridge Phenyl, $(150 \mathrm{~mm} \times 4.6 \mathrm{~mm}, 3.5 \mu \mathrm{mS})$ column. Temperature was maintained ambient, mobile phase used was $0.1 \%$ OPA\& ACN in the ratio of $30: 70 \% \mathbf{v} / \mathbf{v}$. flow rate was maintained at $1.0 \mathrm{ml} / \mathrm{min}$. Diluent used throughout the method was water and ACN $(50: 50 \mathrm{v} / \mathrm{v})$ and the run time was 6 mins. All the samples and mobile phase were degassed for 30 mins and filtered by ultrasonic filtration by using $0.45 \mu \mathrm{m}$ Nylon (N66) $47 \mathrm{~mm}$ membrane filter. Detection was carried out at $210 \mathrm{~nm}$ using PDA detector with an injection volume of $10 \mu \mathrm{L}$. By using the above optimized conditions method was determined.

\section{Preparation of Standard Solution}

$180 \mu \mathrm{g} / \mathrm{ml}$ of Pitolisant is prepared by diluting with mobile phase. This solution is used for recording chromatogram.

\section{Preparation of sample Solution}

Two tablets (each tablet contains Pitolisant 18 $\mathrm{mg}$ ) were weighed and taken into a mortar and crushed to fine powder and uniformly mixed. Tablet stock solution of Pitolisant (1800 $\mu \mathrm{g} / \mathrm{ml}$ ) was prepared by dissolving weight equivalent to $8 \mathrm{mg}$ of Pitolisant and dissolved in sufficient mobile phase and sonicated for 5 min and dilute to $20 \mathrm{ml}$ with mobile phase. Further dilutions are prepared in 5 replicates of $180 \mu \mathrm{g} / \mathrm{ml}$ of Pitolisant was made up to mobile phase.

\section{METHOD VALIDATION \\ Specificity}

Specificity of an analytical method is ability to measure specifically the analyte of interest without interference from blank and known impurities. For this purpose blank chromatogram, standard chromatogram and sample chromatogram were recorded. The chromatogram of blank shows no response at the retention times of drugs which confirms the response of drug was specific

\section{SYSTEM SUITABILITY}

Tailing factor for the peak due to pitolisant in Standard solution should not be more than 2.0 Theoretical plates for the pitolisant peak in Standard solution should not be less than 2000.

\section{Formula for Assay}

$$
\begin{gathered}
\% \text { Assay }=\frac{A T}{A S} * \frac{W S}{D S} * \frac{D T}{W T} * \frac{\text { Average weight }}{\text { Label Claim }} \\
* \frac{P}{100} * 100
\end{gathered}
$$

Where

$\mathrm{AT}=$ average area counts of test (sample) preparation.

$A S=$ average area counts of standard preparation.

$\mathrm{WS}=$ Weight of working standard taken in $\mathrm{mg}$.

$\mathrm{DS}=$ Dilution of working standard in $\mathrm{ml}$.

$\mathrm{DT}=$ Dilution of test (sample) in $\mathrm{ml}$.

WT $=$ Weight of test (sample) taken in mg.

$\mathrm{P}=$ Percentage purity of working standard

$\mathrm{LC}=$ Label Claim $\mathrm{mg} / \mathrm{ml}$.

\section{Linearity}

The linearity of the proposed method was determined by quantitative dilution of the standard solution of pitolisant to obtain solution in concentration range of $18.00 \mu \mathrm{g} / \mathrm{ml}-$ $270.00 \mu \mathrm{g} / \mathrm{ml}$. A graph of peak area versus concentration in $\mu \mathrm{g} / \mathrm{ml}$ was plotted for the drug. The slope, intercept, and correlation coefficient of regression line.

\section{Limit of detection (LOD) and limit of quantitation (LOQ)}

The LOD and LOQ represent the concentration of analyte that would yield to signal-to-noise ratio of 3 for LOD and 10 for $L O Q$. LOD and LOQ were calculated using following formula, 


\section{LOD $=3.3 \sigma / S$}

$L O Q=10 \sigma / S$

where, $\sigma=$ standard deviation of response (peak area) and $S=$ average of slope of the calibration

\section{Method precision}

In method precision, a homogenous sample of single batch should be analyzed 6 times. This indicates whether a method is giving constant results for a single batch. In this analyze the sample six times and calculate the \% RSD

The precision of the instrument was checked by repeatedly injecting $(n=6)$ solutions of $180 \mathrm{ppm}$ of pitolisant).

\section{System precision}

System precision is checked by using standard chemical substance to ensure that the analytical system is working properly. In this peak area and \% of drug of six determinations is measured and \% RSD should be calculated.

\section{Accuracy}

The accuracy of this method was performed at three different levels $(50 \%, 100 \%, 150 \%)$, by the addition of a known amount of standard to the sample at each level. Each level was repeated three times $(n=3)$.

\section{Robustness}

Robustness is the measure of optimized method capacity to remain unaffected by small, but deliberate variations in method parameters such as mobile phase flow rate $( \pm 0.2 \mathrm{~mL} / \mathrm{min})$, wavelength $\mathrm{nm}( \pm 1 \mathrm{~nm})$, and column oven temperature $\left( \pm 1^{\circ} \mathrm{C}\right)$.

\section{Solution Stability}

The solution stability of pitolisant in diluents was determined by storing sample

Solution in tightly capped volumetric flask at room temperature for $24 \mathrm{hrs}$. The amount of pitolisant was measured at different time intervals like 6,12,18 and $24 \mathrm{hrs}$ and results obtained were compared with freshly prepared of pitolisant solution

\section{RESULTS AND DISCUSSION Chromatographic conditions}

X-Bridge phenyl $(150 \mathrm{~mm} \times 4.6 \mathrm{~mm}, 3.5 \mu \mathrm{m})$ Waters column. Temperature was maintained ambient, mobile phase used was $0.1 \%$ OPA \& ACN in the ratio of $30: 70 \% \mathbf{v} / \mathbf{v}$. And flow rate was maintained at $1.0 \mathrm{ml} / \mathrm{min}$. Diluent used throughout the method was water: acetonitrile $(50: 50 \mathrm{v} / \mathrm{v})$ and the run time was 6 mins. All the samples and mobile phase were degassed for 30 mins and filtered by ultrasonic filtration by using $0.45 \mu \mathrm{m}$ Nylon (N66) $47 \mathrm{~mm}$ membrane filter. Detection was carried out at 268nmnm using PDA detector with an injection volume of $10 \mu \mathrm{L}$. By using the above optimized conditions method was developed. Shown in Fig. 2 and Table 1.

\section{Specificity}

Specificity of an analytical method is ability to measure specifically the analyte of interest without interference from blank and known impurities. For this purpose blank chromatogram, standard chromatogram and sample chromatogram were recorded. The chromatogram of blank shows no response at the retention times of drugs which confirms the response of drug was specific.

\section{Linearity}

The linearity of the proposed method was determined by quantitative dilution of the standard solution of pitolisant to obtain solution in concentration range of $18.00 \mathrm{to} 270.00 \mu \mathrm{g} / \mathrm{ml}$. A graph of peak area versus concentration in $\mu \mathrm{g} / \mathrm{ml}$ was plotted for the drug. The slope, intercept, and correlation coefficient of regression line were determined. Shown in Table no2.

\section{SYSTEM SUITABILITY}

Tailing factor for the peak due to pitolisant in Standard solution should not be more than 2.0 Theoretical plates for the pitolisant peak in Standard solution should not be less than 2000.

The results are summarized in Table 3 .

\section{Method precision}

In method precision, a homogenous sample of single batch should be analyzed 6 times. This indicates whether a method is giving constant results for a single batch. In this analyze the sample six times and calculate the \% RSD

The precision of the instrument was checked by repeatedly injecting $(n=6)$.solutions of 180ppm of pitolisant). TableNo: 4

\section{System precision}

System precision was determined by measuring the peak area of six replicate injections of standard solution. The value of $\%$ RSD was found to be $<2$, which ensure the analytical system is working properly. The results of system precision are tabulated in 5 .

\section{Accuracy}

The accuracy of this method was determined by calculating percent recovery of pitolisant in formulation at three different levels $(50 \%$, $100 \%$, and $150 \%$ ). The $\%$ recovery obtained was found to be in the range of 100.2 to $99.8 \%$. The accepted limits of mean recovery is $100.1 \%$ and obtained results were within the 
acceptable range, which indicate recovery values were good, affirming the accuracy of the developed method. The results are summarized in Table 6.

\section{Robustness}

The method was found to be robust when minor changes were made in optimized chromatographic conditions such as oven temperature $\left( \pm 5^{\circ} \mathrm{C}\right)$, mobile phase flow rate $( \pm 0.1 \mathrm{~mL} / \mathrm{min})$, and ratio of mobile phase $( \pm 5 \mathrm{~mL})$. It was observed that there was no marked change in analytical data of the drugs which indicates good reliability during normal usage. The results are shown in Tab; 7 .

\section{Solution Stability}

The solution stability of pitolisant in diluents was determined by storing sample

Solution in tightly capped volumetric flask at room temperature for $24 \mathrm{hrs}$. The amount of pitolisant was measured at different time intervals like 6,12,18 and $24 \mathrm{hrs}$ and results obtained were compared with freshly prepared of pitolisant solution

Acceptance Criteria: The \%RSD values for the assay of the solution stability experiments were calculated and should not more than $2.0 \%$.

\section{Limit of detection}

This is the lowest concentration in a sample that can be detected, but not necessarily quantitated, under the stated experimental conditions.

\section{Limit of quantitation}

This is the lowest concentration of analytic in a sample that can be determined with acceptable precision and accuracy.

\section{Acceptance criteria}

S/N Ratio value shall be 3-10 for LOD solution. $\mathrm{S} / \mathrm{N}$ Ratio Value shall be $20-30$ for LOQ solution shown in Table no: 8

\section{Chromatographic conditions}

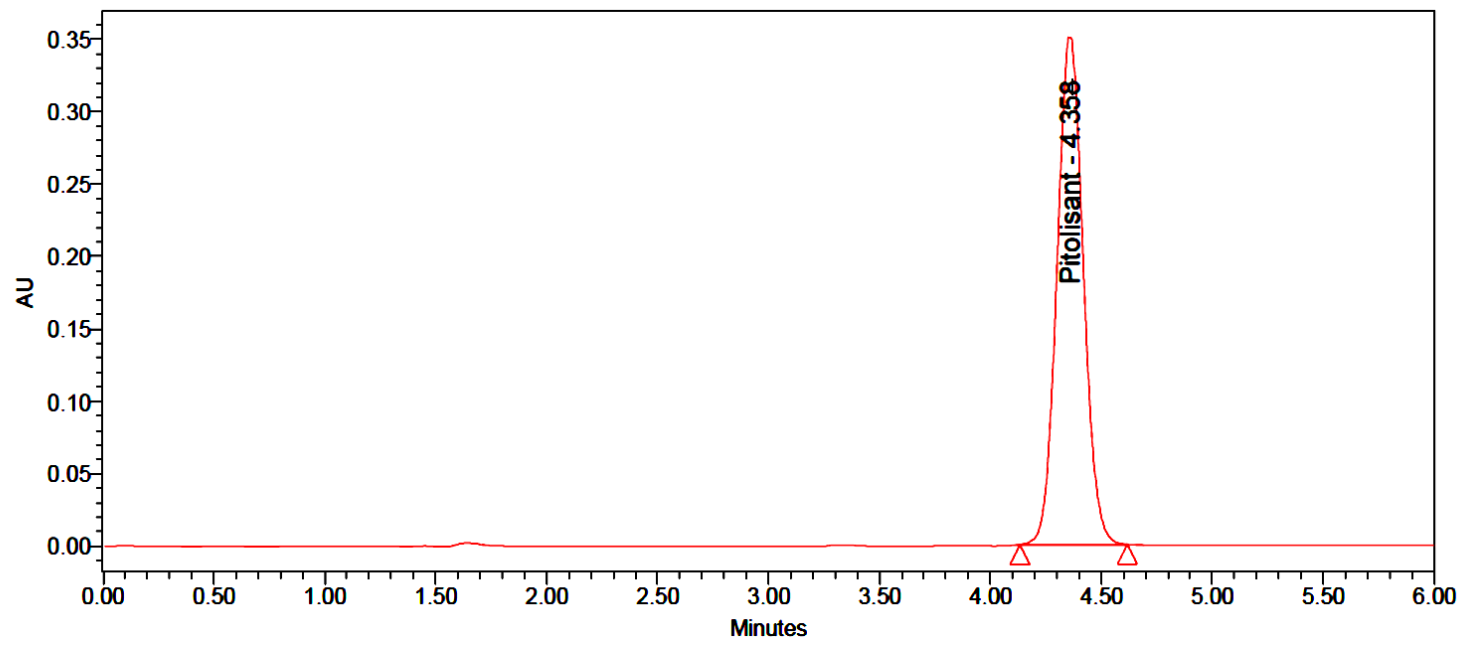

Fig. 2: Typical Chromatogram of pitolisant

Table 1: Optimized chromatographic conditions of pitolisant

\begin{tabular}{|c|c|c|}
\hline S.NO & PARAMETERS & CHROMATOGRAPHIC CONDITIONS \\
\hline 1. & Mobile phase & $0.1 \%$ OPA : ACN $30: 70$ \\
\hline 2. & Column & X-Bridge phenyl 150mm $\times 4.6 \mathrm{~mm}, 3.5 \mu \mathrm{m}$ \\
\hline 3. & Flow rate & $1.0 \mathrm{ml} / \mathrm{min}$ \\
\hline 4. & Column temperature & Room temperature $\left(20-25^{\circ} \mathrm{C}\right)$ \\
\hline 5. & Sample temperature & Room temperature $\left(20-25^{\circ} \mathrm{C}\right)$ \\
\hline 6. & Wavelength & $210 \mathrm{~nm}$ \\
\hline 7. & Tablet volume & $6 \mathrm{ml}$ \\
\hline 8. & Run time & $4.358 \mathrm{~min}$ Pitolisant \\
\hline 9. & Retention time & \\
\hline
\end{tabular}




\section{Linearity}

Table No 2: Linearity of pitolisant

\begin{tabular}{|c|c|c|c|}
\hline \multirow{2}{*}{ S.No. } & Conc. $(\mu \mathrm{\mu g} / \mathrm{ml})$ & Area & \multirow{2}{*}{ Acceptance criteria } \\
\cline { 3 - 3 } & Pitolisant & Pitolisant & \\
\hline 1 & 18.00 & 293054 & \\
\hline 2 & 45.20 & 793514 & \multirow{2}{*}{$\begin{array}{c}\text { Squared co relation } \\
\text { coefficient should be not } \\
\text { less than0.999. }\end{array}$} \\
\hline 3 & 90.00 & 1416209 & \\
\hline 4 & 180.00 & 2814505 & \\
\hline 5 & 225.20 & 3318517 & \\
\hline 6 & 270.00 & 4025617 & \\
\hline
\end{tabular}

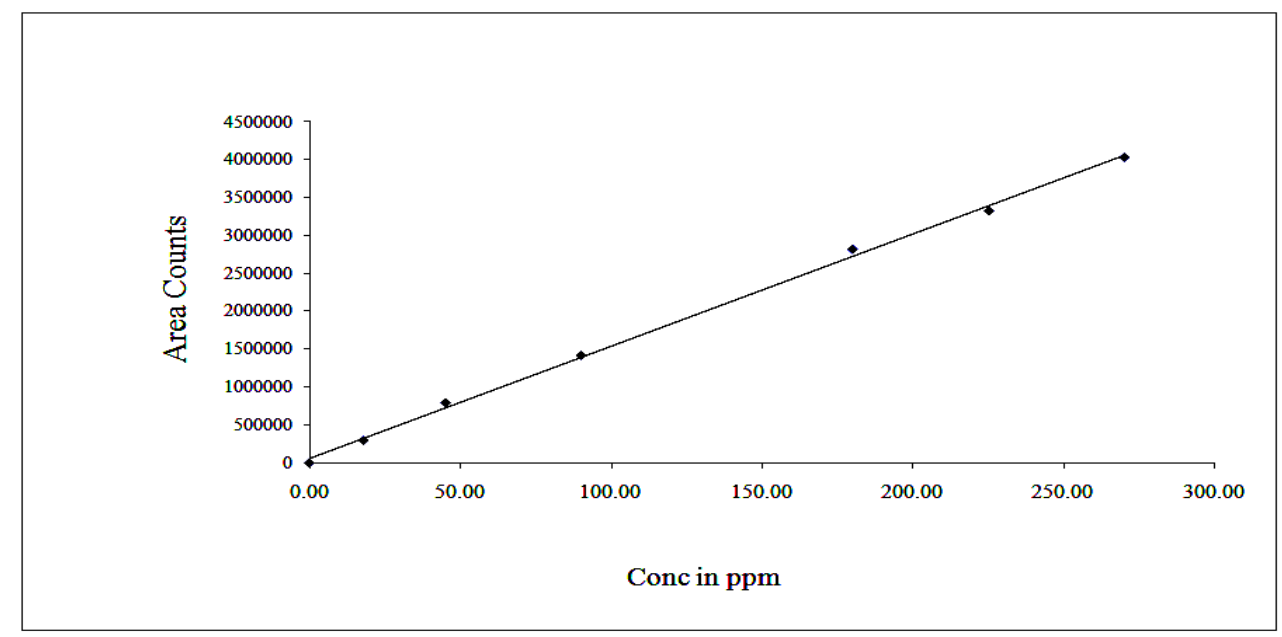

Fig. 3: Linearity graph of pitolisant

Table 3: System Suitability Results of Pitolisant

\begin{tabular}{|c|c|c|c|c|c|}
\hline Injection & $\begin{array}{c}\text { Retention time } \\
(\mathbf{m i n})\end{array}$ & Peak area & $\begin{array}{c}\text { Theoretic } \\
\text { al plates }\end{array}$ & $\begin{array}{c}\text { Tailing factor } \\
\text { (TF) }\end{array}$ & Resolution \\
\hline 1 & 4.346 & 2839455 & 6527 & 1.04 & - \\
\hline 2 & 4.348 & 2861501 & 6530 & 1.04 & - \\
\hline 3 & 4.349 & 2844080 & 6412 & 1.04 & - \\
\hline 4 & 4.356 & 2880398 & 6328 & 1.07 & - \\
\hline 5 & 4.356 & 2881624 & 6324 & 1.07 & - \\
\hline 6 & 4.358 & 2889900 & 6333 & 1.06 & - \\
\hline Mean & & 2866160 & & & \\
\hline SD & & 21108.496 & & & \\
\hline$\% R S D$ & & 0.74 & & & \\
\hline
\end{tabular}

Table 4: Method precision results of Pitolisant

\begin{tabular}{|c|c|c|}
\hline \multicolumn{3}{|c|}{ Pitolisant } \\
\hline S.No. & RT & Area \\
\hline 1 & 4.347 & 2850839 \\
\hline 2 & 4.345 & 2842476 \\
\hline 3 & 4.344 & 2874127 \\
\hline 4 & 4.350 & 2857333 \\
\hline 5 & 4.339 & 2866629 \\
\hline 6 & 4.348 & 2857396 \\
\hline Ave area & & 2858133 \\
\hline St dev & & 11202.83 \\
\hline$\%$ RSD & & 0.39 \\
\hline
\end{tabular}


Table 5: System precision

of Pitolisant

\begin{tabular}{|c|c|}
\hline S.No. & Standard area of Pitolisant \\
\hline 1 & 2839455 \\
\hline 2 & 2861501 \\
\hline 3 & 2844080 \\
\hline 4 & 2880398 \\
\hline 5 & 2881624 \\
\hline 6 & 2889900 \\
\hline Ave area & 2866160 \\
\hline St dev & 21108.449 \\
\hline \%RSD & 0.74 \\
\hline
\end{tabular}

Table 6: Accuracy data of Pitolisant

\begin{tabular}{|c|c|c|c|c|c|}
\hline \multirow[b]{2}{*}{$\begin{array}{c}\text { Recovery } \\
\text { level }\end{array}$} & \multicolumn{5}{|c|}{ Accuracy Pitolisant } \\
\hline & $\begin{array}{c}\text { Amount } \\
\text { taken (mg) }\end{array}$ & Area & Ave Area & $\%$ Recovery & \%RSD \\
\hline \multirow{3}{*}{$50 \%$} & 90 & 1525742 & \multirow{3}{*}{1525437} & \multirow{3}{*}{100.2} & \multirow{3}{*}{0.78} \\
\hline & 90 & 1537252 & & & \\
\hline & 90 & 1513317 & & & \\
\hline \multirow{3}{*}{$100 \%$} & 180 & 2859312 & \multirow{3}{*}{2872186} & \multirow{3}{*}{100.1} & \multirow{3}{*}{0.42} \\
\hline & 180 & 2883118 & & & \\
\hline & 180 & 2874127 & & & \\
\hline \multirow{3}{*}{$150 \%$} & 270 & 4181148 & \multirow{3}{*}{4174889} & \multirow{3}{*}{99.8} & \multirow{3}{*}{0.20} \\
\hline & 270 & 4178082 & & & \\
\hline & 270 & 4165437 & & & \\
\hline
\end{tabular}

Table 7: Result for Robustness of Pitolisant

\begin{tabular}{|c|c|c|}
\hline \multicolumn{2}{|c|}{ Parameters } & Pitolisant \\
\cline { 2 - 3 } & $1.2 \mathrm{ml} / \mathrm{min}$ & $\%$ RSD \\
\hline \multirow{2}{*}{ Flow Rate } & $0.8 \mathrm{ml} / \mathrm{min}$ & 0.15 \\
\hline \multirow{2}{*}{ Organic Phase } & $63: 37$ & 0.34 \\
\cline { 2 - 3 } & $77: 23$ & 0.84 \\
\hline
\end{tabular}

Table 8: LOD and LOQ Results of Pitolisant

\begin{tabular}{|c|c|c|c|c|c|}
\hline \multirow{2}{*}{ S.No. } & \multirow{2}{*}{ Sample name } & \multicolumn{2}{|c|}{ LOD } & \multicolumn{2}{c|}{ LOQ } \\
\cline { 3 - 6 } & & $\begin{array}{c}\text { Conc. } \\
(\mu \mathrm{g} / \mathrm{ml})\end{array}$ & $\mathbf{S} / \mathbf{N}$ & $\begin{array}{c}\text { Conc. } \\
(\mu \mathrm{g} / \mathrm{ml})\end{array}$ & $\mathbf{S} / \mathbf{N}$ \\
\hline 1. & Pitolisant & 0.18 & 6 & 1.8 & 26 \\
\hline
\end{tabular}

\section{CONCLUSION}

Development and validation of RP-HPLC method for the estimation of Pitolisant in bulk and pharmaceutical dosage forms with the facilities and the results are incorporated in this thesis. In conclusion a validated RP-HPLC method has been developed for determination of Pitolisant the bulk and tablet dosage form. The results show that the method was found to be specific, simple, accurate, precise and sensitive. The method was successfully applied for the determination of Pitolisant tablet dosage form. Several analytical procedures have been proposed for the quantitative estimation of Pitolisant separately and in combination with other drugs. So attempt was taken to develop and validate a reversed-phase high performance liquid chromatographic method for the quality control of Pitolisant in pharmaceutical preparations with lower solvent consumption along with the short analytical run time that leads to an environmentally friendly chromatographic procedure and will allow the analysis of a large number of samples in a short period of time.

\section{REFERENCES}

1. Wakix, INN-Pitolisant - European Medicines Agency. Europa EU.

2. WAKIX (Pitolisant) tablets. for oral use- FDA Label.

3. Chwartz JC. The histamine H3 receptor: from discovery to clinical 
trails with pitolisant. $\mathrm{Br} \mathrm{J}$ pharmacol. 2011;163(4):713-721.

4. Calik MW. Update on the treatment of narcolepsy. Clinical efficacy of pitolisant. Nat Sci Sleep. 2017;26;9;127-133.

5. Kotanska M, Kuder KJ, Szczepanska K, Sapa J and Kiec-Kononowicz K. The histamine $\mathrm{H} 3$ receptor inverse agoinst pitolisant reduces body weight in obese mice. Naunyn Schmiedebergs Arch Pharmacol. 2018;391(8):875-881.

6. Nirogi R, Ajjala DR, Kandikere V, Pantangi HR, Jonnala MR, Bhyrapuneni G, Muddana NR and Vurimindi $H$. LC-MS/MS method for the determination of pitolisant: application to rat pharmacokinetic and brain penetration studies. Biomed Chromatogram. 2013;27(11):14311437.
7. Ohayon MM, Priest RG, Zulley J, Smirne $S$ and Paiva T. Prevalence of narcolepsy symptomatology and diagnosis in the European general population. Neurology. 2002; (12):1826-1833.

8. LinJs. Histamine $\mathrm{H} 3$ receptors and sleep-wake regulation. J Pharmacol Exp Ther. 2011;336(1):17-23.

9. Chan CC. Analytical Method Validation: Principles and Practices, in Pharmaceutical Manufacturing Handbook: Regulations and Quality. Edited by Shyne Cox Gad. John Wily and Sons. 2008.

10. ICH Q2A. Text on Validation of Analytical Procedures. Geneva Q2A, in 2005 Incorporated in Q2 (R1). 1994.

11. ICH Q2B. Validation of Analytical Procedures: Methodology. Geneva Q2B, in 2005 incorporated in Q2 (R1). 1996. 